\title{
8
}

\section{The Deployment of an Epistemic Model of Multi-level Governance: A Study of Differences in Hearing}

\section{Anthony Hogan}

Medicine is not the only player upon the stage of what Michel Foucault called 'bio-politics' (Osborne 1996).

The current disability support system is underfunded, unfair, fragmented, and inefficient. It gives people with a disability little choice, no certainty of access to appropriate supports and little scope to participate in the community. People with disabilities, their carers, service providers, workers in the industry and governments all want change (Productivity Commission 2011).

\section{Introduction}

The governance of human communication has been a matter of contention over millennia, particularly for Deaf people, and the lives of those who hear differently from others (henceforth the governance of differences in hearing, since most acquire a change in hearing status rather than being born with it and most retain some experience of hearing). In addition, while there have been multiple players in the shaping of these governmental processes, for the most part people who hear differently from others have been the subject of, rather than the author of, such processes. I assert this position, 
noting two important exceptions: members of the linguistically oriented Deaf Community - the signing world - have often shaped the terms of their own governance, albeit they have often been marginalised from the more dominant phono-centric culture as a result (see, for example, Corker 1998); second, the involvement of deafened people within their own self-help movements such as Self Help for Hard of Hearing (SHHH) and Better Hearing Australia (BHA). From within this group, I note two distinct positions: a smaller cohort who seek to shape their lives according to their own lights; and a second, more common group whose lives and the services they use, be they children, the children's parents or deafened adults, have been the subject of governance processes and concerted efforts of subjectification for over 150 years. It is this latter, most numerate group to which this chapter gives most attention as it considers the development and breadth of governmental processes in this space.

I approach this discussion in several ways. First, the analytical lens provided within Lukes's (1974) theory of the three faces of power enables the framing of a number of important questions about the governance of hearing difference and subsequent social participation. The application of this lens enables questions to emerge that are concerned with why it is that differences in hearing (and disability, more generally) have been a site of governance for so long. Moreover, it enables one to consider the nature of the social agenda around differences in hearing participative capacity and the kinds of interests that have driven it to given ends. Such a lens raises questions about who gets to decide these issues and how such decision-making processes secure sufficient legitimacy, so they can be progressed. It is a study of who wins the battle of ideas and, in turn, is able to secure resources to shape processes that subjugate large numbers of people. While I value Lukes's insight that the third face of power is concerned with the shaping of personal preferences, I have found the analytical lens that can be shaped from Michel Foucault's (1988) approach to the technologies of the self, taking into account more recent modifications to that framework (Akram and Hogan 2015), to be most useful in articulating how governmental structures can be developed and deployed in such a way so as to shape the 'conduct of conduct'.

The core of this framework is straightforward. Certainly, the battle for ideas is constant and enduring, but some ideas find dominance and legitimacy in given places at given times. The social processes that legitimise the emergence of dominance stem from securing what Foucault refers to as the 'the interests of the interested', a more recent variation of Karl Marx's 
insight that the ideas of the ruling class are, in each and every epoch, the ruling culture. Foucault asserts that symbols and meaning systems emerge that are legitimised by the convergence of the interests of the interested. In turn, this process legitimates some practices and beliefs over others, setting in place three additional processes: (i) the funding and formation of institutions and technologies that can be used to shape beliefs and behaviour; (ii) the training of practitioners and the development of techniques of subjugation; and (iii) the application of such techniques on, and by, willing individuals on themselves as they engage in taken-forgranted processes of the formation of the self.

Contrary to the deterministic argument (e.g. Hay and Wincott 1998), individuals can and do have a say over their formation as individuals. It is not the case that people cannot pursue alternatives, just that few have either the courage or the resources, certainly within the deafness milieu, to pursue such alternatives. The Deaf Community is a case in point. Social Scientist Hal Colebatch (University of New South Wales) remarked, following his receipt of a cochlear implant, that the dominant group in deafness, the oralist movement (see Winefield 1987 for further detail), ${ }^{1}$ as they are known, have been so successful in their mission that they are the 'only show in town'. For over 100 years they have been able to shape the agenda, dominating the distribution of funding by ensuring that the policy lens is solely focused on the issues that they wish to see progressed.

It is not the purpose of this chapter to detail how the oralists achieved this position. Rather, the central concern of this chapter is with the governance of hearing difference. Such a governmental arrangement cannot, however, be understood outside the socio-historical context within which it emerged - the milieu from within which the dominant systems of meaning and symbolism grew and found legitimacy. To this end, I first summarise the key arguments of the body of work I have developed over the past 20 years, referring the reader to more detailed studies where further substantiation of the arguments is sought. While from one perspective it could be argued that this is a multi-level approach to governance, it is also epistemic, in that what is most interesting about this approach to governance has been the capacity of the oralist movement to kill off notions of hearing difference, the other, and of alternate ontologies and epistemes of the body (de Sousa

1 The oralist movement took the position that it is a hearing world and that a person should participate in it on the terms of hearing people. A similar argument was taken by patriarchal society with regards the social position of women. 
Santos 2014), and that it serves as its first master the needs of a phonocentric, market-oriented society. It is epistemic (de Sousa Santos 2014), not because of what it bans but for the fact that only some processes of people-formation gain social support, including resources, while those that exist outside this structure are left to wither, as it were, on the vine.

This is a social issue not only because this process systematically extinguishes difference, but also because the movement, whose methods are inherently expensive, ${ }^{2}$ has failed to deliver on its promise that people, by enrolling in such processes, would enjoy equitable participation in society (Hogan and Phillips 2014). In this vein, I document the development of a legitimated capacity to govern the difference in hearing before concluding the chapter with a consideration of what an alternative frame of governance could look like.

\section{The shaping of the habitus surrounding deafness and disability}

Summarising the work of Hogan (1997), it is apparent that, over several hundred years, a variety of community, medical, educational and social interests have been concerned with the governance of hearing difference. Notably, that body of work highlighted the emerging discourse of dependency/independence centred on forms of communication (e.g. sign language verses oral communication) (Winefield 1987) and, in turn, framed the governance of hearing and disability issues generally. This controversy, while driven by concerns focused on securing a given form of social relations amidst a broader threat of social disruption, largely centred on the politics of meaning and symbolism surrounding deafness with regard to supporting the broader functioning of 19th-century Western society. In the case of deafness, people such as Alexander Graham Bell took up this cause with earnest.

Bell observed that devotees of the methods he proposed were even prepared to die for the cause, if it meant that people could be saved from the perils of a deaf world (Winefield 1987; Bruce 1973). In addition to his work on the education of deaf children, Bell also developed an early form

2 Many thanks to Michelle Barry, Executive Officer, Better Hearing Australia, Melbourne, for this insight. 
of an audiometer (a machine that is used to measure hearing impairment). While the institutional and professional arrangements that underpin modern hearing services only began in earnest following World War II, they did, however, draw upon the ontological assumptions underpinning deaf education. As Winefield (1987: 22) observed:

Normal society, Bell maintained, consisted of people who could speak and hear and make use of the English language. The job of educators, therefore, was to prepare deaf children to make their way in the world by being able to communicate in English by speaking and reading lips.

Bell conceived of deafness as disconnecting individuals from a phonocentric society, and that it was the place of hearing services to restore people to participation in such a society. The problem with Bell's conception of speech-based (rather than sign language or augmented forms of communication) social inclusion and participation was that his model sought to eliminate, rather than encompass, difference.

Harlan Lane (1993), a major critic of the bureaucratic implementation of this process, identified the issue at stake as being one of bio-politics, where power is exercised in the lives of people with disability. On the one hand, Lane argues that the governance of deafness results from individualising processes legitimated by formal modes of government. To a certain extent, he also recognises that the governance of Deaf people (that is, members of the signing Deaf Community) is situated within a broader system of governance concerned with the regulation of disabled people and others whose social status came to be considered marginal. Lane stops short, however, from describing how such a process of governance came into being, leaving the reader with the sense that people who design and run hearing services, as an example, simply had the power to make it all happen. As such, Lane's position could unintentionally suggest a more simplistic understanding of how power is deployed, as though power could be possessed like a side gun slung across the waist band. Foucault's understanding of power is far more complex:

Power is not something that is acquired, seized, or shared, something that one holds on to or allows to slip away; power is exercised from innumerable points, in the interplay of non-egalitarian and mobile relations (Foucault 1978: 94). 
If Foucault's insights on the social processes of the formation of the self are correct, then one ought to be able to document how power comes to be exercised and focused on the formation of people who hear differently from others. At issue within such an analysis is that governance processes are based on the seemingly legitimate, taken-for-granted, unquestionable commonsense way in which things get done, such that one way of acting would seem the only way one would act in a given circumstance. It is this taken-for-grantedness about the deficits of hearing difference and its inherent threat to broader society, along with assumptions about the validity of phono-centricism, that underpin the emergence of a multifaceted approach to the governance of hearing difference. Such an approach resulted from the collaboration of institutions and professions, situated within a social context shaped by these specific meanings and economic relations, and came into being in such an unexceptional process that technologies and specific techniques of self-formation could be brought to bear on given groups of individuals in such a way as to seek to influence the behaviour of those people in ways that seem self-evident.

This chapter, then, examines the developments of such modern hearing services, considering as it does the models of individual formation that were, in turn, brought to bear on the person who hears differently from others, while acknowledging the dominance of one form of governance over others. Moreover, this chapter seeks to make apparent the fact that it is possible for individual and institutional actors to deploy a governmental process not only without the consent or involvement of those most affected, but also because of processes of personal formation and socialisation that result in people enrolling themselves in procedures and using technologies despite the fact that they may not improve their social position.

\section{The development of publicly funded hearing services in Australia}

Publicly provided hearing rehabilitation services commenced in earnest in America following the World War II, with service provision focused on veterans (Gaeth 1979). Interestingly, the early development of hearing services was centred on a medical model of the body that focused services on an integrated model of delivery concerned with the wellbeing of the whole person (Gaeth 1979). Given the notable limitations of the hearing devices available at that time, concern existed that the medical model over-promised on the extent to which the offered interventions (such as 
surgery, hearing aids, lip-reading training) could meet the needs of returning veterans. Notably, the service model saw that a 'man is more important than his ears' (Gaeth 1979: 6). The service model was centred on two principles: the positive and negative of hearing loss. With regards to the positive, the program sought to equip the person with normal functioning using hearing aids, speech reading and related tools. As such, a foundational step in the development of this service model was the taken-for-granted acceptance of a deficit model of hearing, remediated, as it were, by hearing aids and supplementary training designed to maximise the benefits the device could offer. Interestingly, though, the model acknowledged the limitations of the devices at that time.

The negative approach to the program was constructed as follows:

The rehabilitee must learn new ways of getting along in a world that is dependent on communication. If he wears a hearing aid, he must learn to think and act like a person who wears a hearing aid, not like a person who is perfectly normal but cannot hear well. He must prepare himself to meet the thoughtless attempts of others to communicate with him (Gaeth 1979: 6).

Central to the negative approach was the taken-for-granted acceptance of the ontology underpinning communicative relations - it is a hearing world and one must learn to live in it as a hearing person. Similarly, it was taken for granted that, from an interactional point of view, the person whose hearing was different from others would adapt themselves to the needs of dominant society, despite the fact that such a process could be difficult and/or stigmatising.

In Australia, the resulting, Commonwealth-funded service-delivery model was based on a military style of teaching that was matter of fact, if not somewhat confrontational; services were concerned with delivering help 'which lays the cards on the table and gives help on how to cope' (Gaeth 1979: 5). In addition, hearing services were not voluntary, but rather soldiers were 'sent' for rehabilitation (Gaeth 1979). As military personnel, the participant's job was to be in the program. The power to compel people to participate in hearing services also serves to underpin the command-and-control values at the centre of many hearing services today. Within the audiological sector, there is an evident culture of annoyance with people who will not take appropriate action to manage their hearing loss or use their hearing aids, as though they were somehow disobeying orders. 
Setting aside the values that guided the delivery of services, the idea of providing people with access to assistive listening devices as well as support in managing everyday interactions was considered to be a form of audiological Camelot $^{3}$ (Ross 1997). Some of the values underpinning the service model also foreshadowed the emergence of the social model of disability (Oliver 1996). Henoch (1979) argued that services for older people who heard differently needed to address the social aspects of hearing by working with families and people who regularly interacted with the person to enable them to participate in those interactions. These models of intervention similarly did not question the assumption about the primacy of the taken-for-granted rules of phono-centric communication. Rather, a supportive, adherencecentred model was put in place where people who heard differently were offered support while they learnt to fit in with others and the way that taken-for-granted phono-centric communication took place.

Like all fairy tales, the days of Camelot were numbered. Within barely a decade the then comprehensive approach to the delivery of hearing services was abandoned. This appears to have occurred as a result of three intersecting factors: the resource demands placed on the field by the rubella epidemic (which I discuss further below), the resulting reduced clinical time available to work with adults and the subsequent over-reliance on the technical competencies of hearing aids.

The then Commonwealth government-run National Acoustic Laboratory (NAL) (now Australian Hearing), was the primary institutional mechanism through which hearing services were deployed at the societal level. Cordell's (1978) history on the development of this service model highlights several important points. Cordell affirms that hearing services in Australia, as elsewhere, were developed in response to the needs of deafened veterans returning from the war. ${ }^{4}$ From a 'public health' perspective, the need for the service was at an epidemic level, given the number of veterans with hearing loss. The service model was deficit based and focused on the provision of hearing aids as well as communicative support and training provided by what became known as adult aural rehabilitation specialists. The outcomes that could be delivered by hearing aids were also limited, however, and, as such, communication training and support services were developed by the community sector, on a voluntary basis, with little financial support. It was in this context that the community organisation BHA emerged, providing

3 A utopian notion that this was the ideal form of hearing services consisting of the provision of devices and psycho-social support.

4 See also tinyurl.com/hearingservices [Accessed: 17/12/2014]. 
further support and communication training on a voluntary basis. This service particularly taught people to lip-read and to develop their social skills, and it provided a much-needed source of social support. Even today, those older adults who do not fare so well with cochlear implants often seek support from BHA.

The epidemic of war-related hearing problems was followed by the rubella epidemic (Upfold and Isepy 1982), which had a serious impact on NAL resources, which needed to be focused on this new and pressing service need. Increasingly, resources that were used to provide in-depth services for adults were replaced with expert services concentrated on children with fairer hearing. Cordell (1978) shows that again NAL essentially focused on the provision of hearing aids; but child aural rehabilitation specialists also emerged as a form of service provider with NAL. Services concerned with communication training were, again, time intensive more so for children who were, as yet, to fully establish language, complete school or attain marketable employment skills. Cordell (1978) points out that, in time, NAL continued to focus on the delivery of hearing aids while state-funded schools for deaf children delivered the more timeintensive programs of communication training. In subsequent decades, government-funded services for people who hear differently from others were extended to certain groups of eligible aged pensioners in Australia.

Summarising this section, we see then that hearing services were based on a taken-for-granted medical, phono-centric, deficit model of the body. They deferred to the dominant communicative culture and worked to enable people with impaired hearing to participate in society on that basis. Its focus was on fitting devices and not on the social emancipation of people who hear differently from others.

\section{Workers compensation hearing services}

The postwar period also saw the development of primarily state-based hearing services for workers whose hearing was changed as a result of sustained exposure to loud noise at work. ${ }^{5}$ Services for this group became an issue in the 1950s and 1960s (Milne v International Combustion Australia Ltd [1953] WCR 80). A particular problem in law was that

5 Comcare is a Commonwealth agency with responsibility for workers compensation services for Commonwealth employees, including people in the armed services. 
industrial deafness (as it was called) did not result in an incapacity to work and not having an incapacity to work meant that the worker, in this case Mr Milne, did not have a date of incapacity. This legal problem 'came to a head' in Commissioner for Railways $v$ Coates (1960) WCR 88 in the NSW Supreme Court, which provided a simple statutory formula for determining the date of injury; that is, the date of the worker's application is deemed to be the date of onset of the disease.

The fact that the worker did not have incapacity to work, however, also by inference meant that the worker did not have an incapacity that required intervention for the purpose of restoring their ability to work. In law, such interventions are defined as reasonably necessary treatments, a definition that is also applied to Australia's recent National Disability Insurance Scheme (NDIS). In the case of industrial deafness, treatment for the resulting disability fell through a gap since the person could work and thereby retain earning capacity. Treatment and rehabilitation services concerned with equipping the person for work were not designed to address the implications of an industrial injury that resulted in the person having a disability but not necessarily an impediment to work. As Bohle et al. (1991: 281) argue, the broad objective of workers compensation legislation is for 'the provision of income security to injured workers, requiring employers to fund such benefits, enhancing and facilitating the rehabilitation of injured workers'. Similarly, Luntz (1975: 65-66) points out that compensation relates primarily to a loss of earning capacity: 'the impairment [a] the ability of that person to engage in work that is useful or gainful; or $[\mathrm{b}]$ the wellbeing of that person, or both'.

An interesting point of contrast exists between this model and other models of hearing services. For people with other forms of acquired hearing impairment, services were designed to fit the person back into society. Within the workers compensation system, the reverse applied. Since the worker continued to fit in at work, no service was required, irrespective of the impact of impaired hearing on the worker or their family.

During the late 1980s, Australian Government departments adopted the policy that the government should not provide a public service that could as readily be provided by the market. This policy took effect in hearing services in 1996 with the introduction of a voucher system that would enable 'greater private sector involvement in the provision of government funded services'. ${ }^{6}$ The Office of Hearing Services (OHS) was,

6 tinyurl.com/hearingservices [Accessed: 17/12/2014]. 
in turn, established within the Commonwealth Department of Health and Ageing (DOHA) to administer this program. As at December 2013, there were 2,637 accredited service outlets in Australia where the hearingservices model could be accessed. Assuming an Australian population of four million people who hear differently from others, this represents one hearing-services outlet for approximately every 1,500 people. As such, this model of service delivery is pervasive in Australia but, nonetheless, it is essentially a broadly developed infrastructure for the deployment of hearing aids.

In addition, while the nation has a highly developed infrastructure for the deployment of hearing aids, persistent concerns have been held about the adequacy of this service model or the practical utility of hearing aids. In response to consistent complaints from the community sector about the limits of hearing aids, the expense of delivering such a program and the inadequacy of the service model vis-à-vis social outcomes, the OHS introduced a Rehabilitation Plus program in 2008. While this program was sold as being put in place to address some of the social issues facing people who hear differently, its primary aim was to get people to use the hearing aids with which they had been provided. Non-use of hearing devices remains a contentious issue. For example, OHS reported that its data showed about 30 per cent of people who received hearing aids did not use them. ${ }^{7}$ Soon after, they reported to the Australian Senate that 10-13 per cent of people with devices did not use them. This was in contrast to data reported in Lancet (Smeeth et al. 2002) that about 40 per cent of people with hearing aids do not use them. The most recent Australian data (produced by the research company instinct and reason) shows an average rate of device non-usage at 28 per cent.

Despite the privatisation of adult hearing services in Australia, the current Australian Government provider, Australian Hearing (previously NAL), remains the dominant player in hearing services and the funding of the majority of hearing services is federally controlled. Moreover, across the spectrum of hearing-service providers in Australia, there are few practising audiologists who did not complete their initial postgraduate service with either NAL or Australian Hearing. Indeed, these institutions have served as the developmental ground for much of the profession and, as such, serve as the key institutions that shape and reinforce the service-delivery values of Australia's hearing services.

\footnotetext{
7 OHS, personal communication, 7 December 2011.
} 
A review of their respective websites is informative. The NAL website ${ }^{8}$ promotes its product development and range of research projects. Its research is concerned with:

1. assessing hearing loss; e.g. techniques and technologies

2. rehabilitation procedures; e.g. the relationship between speech perception and production with linguistic, educational and social outcomes; developing prescriptive procedures to enable the combination of acoustic and electric stimulation; the relationship between frequency compression; and educational outcomes

3. rehabilitation devices - research into hearing aids, self-fitting hearing aids, cochlear implants and the barriers to people accepting hearing aids

4. engineering technologies; e.g. the development of an automatic auditory brain response (ABR) audiometer.

In short, NAL researches hearing aids and related technologies and is concerned with the impacts and outcomes associated with these products. The website of Australian Hearing 9 prominently promotes the use of a wide range of hearing aids and devices. It provides its services to people who are eligible for support under the Australian Government's Hearing Services Program, including Pensioner Concession Card holders, veterans, Indigenous people and people under 25 years of age. The website makes it clear that Australian Hearing essentially offers hearing testing and a device-fitting service.

The extensive range of private service providers that are accessible in Australia can be found on the OHS website. Similar to Australian Hearing, the range of services provided by the private providers is inherently consistent with the scope of works funded by OHS. Without doubt, there are exceptions to the rule, with some providers offering an approach more informed by social- and citizen-based models of disability; fewer still, however, engage in emancipatory processes. The evidence in support of the view that the scope of service delivery remains narrow is borne out in OHS's published budget papers, which demonstrate that less than 5 per cent of eligible clients have been provided with access to alternate models of service. ${ }^{10}$

8 www.nal.gov.au [Accessed: 20/03/2014].

9 www.hearing.com.au/category/hearingsolutions/ [Accessed: 20/03/2014].

10 See for example www.health.gov.au/internet/budget/publishing.nsf/Content/2011-2012_Health_ PBS [Accessed: 23/03/2012]. 


\section{Adding the multi to the levels of governance of hearing services}

We have seen so far that, from the audiological perspective and irrespective of governmental processes, Camelot existed in the golden days of the postwar period. Looking back at this period, one can see that the initial hearing services were comprehensive, providing both hearing devices as well as social support. At the same time, the service design was steeped in taken-for-granted assumptions that underpinned the medical, phono-centric model of the body, while the service model was based on an authoritarian, hierarchical medico-military culture. Socially, a compliance model was put in place wherein people were provided with skills development in coping with discriminatory and stigmatising behaviours. In time, the marginalisation of the provision of non-device based services occurred. Certainly, by the mid-1960s, questions were raised about the credibility of audiologists engaged in the provision of client-support services, commonly referred to then as aural rehabilitation:

The drift from aural rehabilitation has been so extensive that it represents a change in the basic direction of the field ... The audiologist who voluntarily chooses the role of rehabilitation worker must be truly dedicated, for he runs the danger of being considered incompetent for other functions by his peers (Rosen 1967, cited in Ross 1997).

Despite such marginalisation, a range of people-centred, non-device and often community-based service models continued to be developed and delivered within pockets of excellence across the world (Pengilley 1975; Plant 1976, 1977; Anderson 1991; Hetu and Getty 1991; Getty and Hetu 1991; Hogan et al. 1994; Erdman et al. 1994; Sherbourne and White 1997; Westcott and Kato 1998).

Beyond models of service such as those offered by BHA, communitybased service delivery models, although poorly resourced and few in number, also began to emerge in Australia in the 1970s. The most notable service model in Australia was founded by the Victorian Hearservice. Their program identified three main aims (Pengilley 1975):

1. alleviate anxiety in the individual who has the problem, and assist him [sic] to achieve better communication skills

2. assist the individual's family and his human environment

3. educate the public through a HEAR Promotion Program. 
The program sought to address both the social as well as individual, familybased aspects of living with impaired hearing. By the 1980s, the state-based Hearservice offered two courses: Coping Skills I and II. These courses were offered in small groups, essentially for older people with impaired hearing. The programs were offered over a series of weeks and focused on developing people's skills through the use of a range of communication tactics. The 1980s also saw collective groups emerging, such as a national consumer peak group then known as the Australian Deafness Council, which, in time, was renamed, at the insistence of the Commonwealth, as the Deafness Forum of Australia. On various occasions, this peak group has attempted to launch a series of social education programs aimed at improving social participation and reducing the stigmatisation of people who hear differently from others. Since their funding base is less than that of your average neighbourhood centre, however, it is reasonably given that their capacity to be effective is severely constrained. As Jordan and Halpin (2006) state, given that the dispensing of hearing aids and devices is the primary policy for hearing services in Australia, any other form of service delivery is unlikely to receive much support.

Some of the early service models (e.g. Plant 1976, 1977; Westcott and Kato 1998) had their origins within government-based hearing services programs. Plant, for example (1976: 15-19), remarks that the NAL recognised that the mere fitting of a hearing aid is not a satisfactory solution to the many problems confronting' people who hear differently from others. While Plant argued that group-based and individual followup programs were necessary, his perspective was framed in phono-centric values, since he saw the purpose of such support as giving people 'a realistic attitude' to managing their difficulties.

In the late 1990s, the then Australian Hearing Services offered seriously deafened adults access to intensive communication training and support via residential workshops (Westcott and Kato 1998). Participants in cochlea implant programs were also beginning to take part in group-based interventions. At the time, similar programs could be found in other countries across the world, such as Denmark, which, in turn, influenced the development of the service base offered within Australia (Anderson 1991: 51-57). However, unlike most countries, the Danish programs tended to be offered to any person with impaired hearing, not just those with more severe degrees of impairment. Anderson (1991) reported that, in the Danish program, following hearing aid-fitting, allocated individuals were then 'slotted' directly into a group program consisting of 
two hours one week followed by a one-hour session the following week. Participants requiring further assistance could return at any time. Those requiring further help could be offered two other courses of eight twohour small group sessions. As per Anderson's (1991) description of the program, they too were highly phono-centric in nature. She notes that the first course aimed to:

- give participants insight and knowledge of their handicap and acceptance of hearing loss

- cover basic anatomy, physiology and pathology of the ear, diagnosis, audiograms (including recruitment and tinnitus), hearing tactics, lip reading and relaxation techniques.

The second course aimed to enhance:

- auditory and visual awareness

- lip-reading and body-language reading skills

- skills in natural signing and gestures, mimicry, acceptance of hearing disability

- ability to manage stress.

Reports of similarly designed programs (e.g. Kirby and Rogan 1981; Della Valle 1988) can be found in the literature of the time. At an individual level, such programs are well and good as they equip people to cope with unfavourable social interactions. They are, however, not without their limits because they do not address the social relations of hearing. Rather, they promote a message of accept, adapt and comply with the demands of the phono-centric society.

This results in two problematic outcomes. First, people who hear differently from others are rightly reluctant to use such tactics, as they risk further stigmatising themselves. Second, because the need for interactive change has not been socially legitimated, the capacity at the individual level to leverage change is limited. As one person remarks:

I might add that some of my friends, even knowing of my hearing difficulties, still talk to my back or with faces turned away and then wonder why I don't answer them (Letter to the Editor, The Senior, February 2012). 
And another person writing to the same newspaper remarked:

People constantly laugh when I repeat what I heard as it bears no resemblance to what they are saying. While I appreciate the humour of the situation, it can be embarrassing. I just smile and don't respond (Letter to the Editor, The Senior, February 2012).

Today, a fledging infrastructure of community-based hearing services still exists in Australia. The design of such services confused by their seeking to address the needs of Deaf people as well as people who hear differently from others, as though, yet again, their social, cultural and communicative needs were all alike. Most services retain a strong focus on accessing technology and some remain tightly enmeshed within the medical model of service delivery.

\section{The governance of other community-based hearing services}

The historical development of hearing services in Australia is anomalous to the structuring of the nation's other disability services. Most disability services in Australia came under the auspices of the then National Disability Agreement (Council of Australian Governments 2009) and were funded either through the then Commonwealth Department of Family and Community Services (now the Department of Social Services) and Indigenous Affairs (FaHCSIA) (and presently within the Prime Minister's department), or through community service departments found within state government departments. The annexation of hearing services within the medical model in health has had profound consequences for the development of alternative forms of service delivery. Unlike services for the Deaf Community (see, for example, detail of services funded in this sector in Access Economics (2006)), which are, for example, widely funded as disability services, comparatively few alternative service models exist for people who hear differently from others, as funded under the NDA. Moreover, since the development of Australia's NDIS in 2013, the majority of hearing services have remained annexed within health services. While attempts have been made to shift hearing services for those with severe to profound impairment to the NDIS, the movement of children's services, in particular, has been fiercely resisted by service providers. Their resistance centres on the extent to which a highly decentralised model of service provision that requires a 'high level of expertise' can be delivered by 
generalist providers of disability services. At the time of writing, these policy disputes have not been resolved. It would appear, however, that services for adults with hearing impairment that is severe or 'worse' and aged less than 65 years will be provided under the NDIS.

The community-based services that do exist operate under a number of structures. Some service models closely align themselves with the medical model, having medical specialists as their patrons, and work to continue to address the support needs of people that cannot be addressed by hearing devices. A variety of community-based services have followed aspects of the British model, where centres provide people with access to assistive listening devices other than hearing aids. While these services address an important need, they similarly reinforce a value that depicts the participation needs of people who hear differently from others as being those that can be addressed through the provision of technology alone, without addressing the structuring of the social relations of hearing.

A small group of service providers have developed communicationtraining programs that equip people to more cleverly manage the everyday challenges of communicating in adverse settings. While generally I am supportive of these kinds of interventions, since they equip people to better manage potentially stigmatising social situations, my support for them is qualified by the extent to which such services also work to change the structuring of communication at the societal level and address the social position of people who hear differently. For the most part, these kinds of services receive little, if any, funding support. Some children's services receive funding from the Department of Social Services under the Better Start program. ${ }^{11}$

Taken altogether, there are very few alternative support models available to people who hear differently that do not fall within the medical, phonocentric, device-based model. Considering the Foucauldian model of personal formation that I presented earlier, I contend that hearing services at the institutional, technological and practitioner level are focused on the formation of individuals so that they adhere to the dominant structuring of an existing, albeit unfair, hearing society and are based on an ablest model of social relations. Notably, a good proportion of people who hear differently are dissatisfied with this model of service delivery (Chisolm et

11 www.dss.gov.au/our-responsibilities/disability-and-carers/program-services/for-people-withdisability/better-start-for-children-with-disability-initiative [Accessed: 12/12/14]. 
al. 2007; Smeeth et al. 2002). The individualising nature of the service model and the imbalance in power relations, however, maintain the status quo. One person who hears differently remarks on this experience:

Over the past 20 years I have had 5 sets of hearing aids, some of them with remote controls but none of them very satisfactory as all they do is amplify all the noises around us, including the ones we don't want to hear such as background noise/music. When having new hearing aids fitted recently I was told I needed to concentrate better. (Letter to the Editor, The Senior, 9 February 2012)

Central to the problems with hearing services that are identified in this chapter is the narrowly constructed base for the governance of these services where, for the most part, end users have little, if any, input into service design and where consumer groups are routinely excluded from funded service models. The rationale and strategy for funding services for people who hear differently needs to be reviewed so that the narrow focus on needs and outcomes presently embodied within a device-centric system may be expanded in keeping with the principles of the co-design of disability services. Specifically, the primary focus of funded services for people who hear differently needs to address the basis upon which people can participate in community life by having equal access to enabling social processes and being able to enjoy a level of socio-economic wellbeing similar to all other citizens. Within such services, the need for social change and achieving social outcomes is given priority over assessments and prescriptive services.

\section{Governing governance}

One model of hearing services, then, takes dominance over alternative models of service delivery and support - the device-centred medical model, underpinned as it is by its logic of accept, adapt and comply. This model of hearing services sits within a governance structure that is focused on the reproduction of the individual as a hearing person. The service model is based on:

- unexamined assumptions about the negativity of the experience of disability

- the privileging of input, device-based interventions over social position and social outcomes 
- the absence of any endeavours to change the social relations of hearing, including the social structuring of communication or addressing the acoustic accessibility of built environments

- a particular form of governance of people with disability.

The benefits of device-based interventions in their own right, as beneficial technologies, are not contested. Indeed, elsewhere I have demonstrated the benefits such technologies can have in the lives of people who hear differently from others (see, for example, Hogan 2001; Hogan et al. 2009). What is disputed is the process of governance that focuses social pressure upon people who hear differently from others to adopt one way of managing hearing over viable alternatives. From the social perspective, people who hear differently from others have become an object of processes of subjectification. This process of governance shapes the meaning of deafness and implicitly links it with the longer-standing discourse on disability that is concerned with the threat disability poses to liberal economy through constructed, indeed privileged, notions of social and economic dependency.

Over the past 70 years, institutional processes encompassing formal government, industry, the academy and charity-based services have gradually been formed into an organised system that channels the opportunities offered to the person with impaired hearing, with a view to promoting the formation of the self into a being who is socially and economically independent. The ethical responsibility for personal reformation falls to the individual who, in turn, may attempt to conform to the demands placed upon him/her.

When confronted with this dilemma, the individual may readily accept the situational assessment and remedies offered within the existing process of governance and willingly seek to reform themselves as hearing people. To the extent that such self-subjugation works, this intervention and its consequences enable the individual to maintain his/her social attachments and provide a strategy for living within the hearing world. Opportunities for humanising the process do exist but individuals generally need access to people or processes that validate their actions. Nonetheless, most people do not reach this point of decision-making. Rather, services engage the individual into specific processes of self-reformation before he/she has had the opportunity:

- to critique the social meanings attributed to deafness

- to be informed about all the options that are available to him/her 
- to consider the consequences of pursuing such options

- to talk through such processes with well-informed, non-tokenistic peer advocates who have already been through such processes

- to negotiate this process with his/her family from an equal position of power.

If meaningful social outcomes are to be achieved by people who hear differently, then service providers need to work with, rather than on, disabled people (Oliver 1996). Hearing services are centred on a value base that, if it was ever right, is long overdue for a review. Within the historical milieu underpinning hearing services, it was deemed acceptable for professionals to determine the range and nature of services to be offered to, or provided to, people who hear differently. Things have changed. The social impact of various social movements over the past 30 years has seen patriarchy, science and medicine lose much of their privileged positions in broader society. The interests and legitimacy of oppressed groups, such as people of colour, minority ethnic communities, women, and gay and lesbian people, have gradually received recognition, as has the politics of difference in general and the social model of disability in particular. Throughout the world, disability groups are contesting the medicalisation of disability and the marginalisation of disabled people. While the Deaf Community has been at the forefront of such social change, people with impaired hearing have been less willing to align themselves with what many consider to be a stigmatised identity.

\section{Acknowledgement}

A preliminary version of this paper appeared in ENT and Audiology News (United Kingdom), May 2009.

\section{References}

Access Economics (2006). Listen Hear! The Economic Impact and Cost of Hearing Loss in Australia. CRC for Cochlear Implant and Hearing Aid Innovation and Vicdeaf, Melbourne.

Akram, S. \& Hogan, A. (2015). On Reflexivity and Breaches to the Routinisation of Everyday Life. British Journal of Sociology, 66(4): 606-25. doi.org/10.1111/1468-4446.1215 
Anderson, M. (1991). Services For Hearing Impaired People and Training for Health Workers in Denmark. Auration No. 1, National Acoustic Laboratory, Chatswood.

Bohle, P., James, C. \& Quinlan, M. (1991). Occupational Health and Safety Law: Workers' compensation, rehabilitation and injury impacts. In: Quinlan, M. \& Bohle, P. (eds) Managing Occupational Health and Safety in Australia: A Multidisciplinary Approach. Macmillan Education Australia, South Melbourne, pp. 243-83.

Bruce, R.V. (1973). Bell: Alexander Graham Bell and the Conquest of Solitude. Cornell University Press, Ithaca.

Chisolm, T.H., Johnson, C.E., Danhauer, J.L., Portz, L.J., Abrams, H.B., Lesner, S., McCarthy, P.A. \& Newman, C.W. (2007). A Systematic Review of Health-Related Quality of Life and Hearing Aids: Final report of the American Academy of Audiology Task Force on the health-related quality of life benefits of amplification in adults. Journal of the American Academy of Audiology, 18: 151-83. doi.org/10.3766/ jaaa.18.2.7

Cordell, J. (1978). Early History of National Acoustic Laboratories. Internal Report No 6. National Acoustic Laboratories, Australian Department of Health, Millers Point, Sydney.

Corker, M. (1998). Deaf and Disabled, or Deafness Disabled? Towards a Human Rights Perspective. Open University Press, Buckingham.

Council of Australian Governments (2009). The National Disability Agreement. Canberra, www.federalfinancialrelations.gov.au/content/ npa/national_agreements/national-disability-agreement.pdf

Della Valle, E. (1988). Aural Rehabilitation for the Elderly. MA Thesis, Macquarie University, 1988.

de Sousa Santos, B. (2014). Epistemologies of the South - Justice against Epistemicide. Paradigm Publishers, Boulder.

Erdman, S.A. (2009). Therapeutic Factors in Group Counseling: Implications for audiologic rehabilitation. Perspectives on Aural Rehabilitation and Its Instrumentation, 16(1): 15-28. doi.org/10.1044/ arii16.1.15 
Erdman, S.S., Wark, D.J. \& Montano, J.J. (1994). Implications of Service Delivery Models in Audiology. Journal of the Academy of Rehabilitative Audiology. 27: 45-60.

Foucault, M. (1978). The History of Sexuality Volume One-An Introduction. Penguin, London.

- (1988). Technologies of the Self. In: Martin, L., Gutman, H. \& Hutton, P.H. (eds) Technologies of the Self - A Seminar with Michel Foucault. Tavistock, London, pp. 16-49.

Gaeth, J.H. (1979). A History of Aural Rehabilitation. In: Henoch, M.A. (ed.) Aural Rehabilitation for the Elderly. Grune and Stratton Inc., New York, pp. 1-21.

Getty, L. \& Hetu, R. (1991). Development of a Rehabilitation Program for People Affected with Occupational Hearing Loss. 2: Results from group intervention with 48 workers and their spouses, International Journal of Audiology, 30(6): 317-29. doi.org/10.3109/00206099109072894

Hay, C. \& Wincott, D. (1998). Structure, Agency and Historical Institutionalism. Political studies, 46(5): 951-57. doi.org/10.1111/ $1467-9248.00177$

Henoch, M.A. (ed.) (1979). Aural Rehabilitation for the Elderly, Grune $\&$ Stratton, New York.

Hetu, R. \& Getty, L. (1991). Development of a Rehabilitation Program for People Affected with Occupational Hearing Loss: A new paradigm. International Journal of Audiology, 30(6): 305-16. doi. org/10.3109/00206099109072893

Hogan, A. (1997). Issues Impacting on the Governance of Deafened Adults. Disability And Society, 12(5): 793-805. doi. org/10.1080/09687599727056

—. (2001). Hearing Rehabilitation for Deafened Adults - A Psycho-social Approach. Wiley (Whurr) Publishers Ltd, London.

Hogan, A., Ewan, C., Noble, W.G. \& Munnerley, G. (1994). Coping with Occupational Hearing Loss: The University of Montreal Acoustics Group Rehabilitation Programme. An Evaluation Study. Journal of Occupational Health \& Safety - Australia and New Zealand, 10(2): 107-18. 
Hogan, A., O'Loughlin, K. \& Kendig, H. (2009). The Impact of Hearing Loss on Personal Health - A Threshold Effect Model. Journal of Ageing and Health, 21: 1098-111. doi.org/10.1177/0898264309347821

Hogan, A. \& Phillips, R. (2014). (We Want) a Fairer Hearing. University of Canberra.

Jordan, G. \& Halpin, D. (2006). The Political Costs of Policy Coherence: Constructing a rural policy for Scotland. Journal of Public Policy, 26(1): 21. doi.org/10.1017/s0143814x06000456

Kirby, V.M. \& Rogan, S.D. (1981). A Four Week Group Communication Training Programme for Adults. Journal of the Aural Rehabilitation Association, 14(Fall): 8-16.

Lane, H. (1993). The Mask of Benevolence. Disabling the Deaf Community. Vintage Books, Random House, New York.

Lukes, S. (1974). Power - A Radical View. Macmillan Press, London. doi.org/10.1007/978-1-349-02248-9

Luntz, H. (1975). Compensation and Rehabilitation. Butterworths, Sydney.

Oliver, M. (1996). Understanding Disability - From Theory to Practice. Macmillan, London. doi.org/10.1007/978-1-349-24269-6

Osborne, T. (1996). Security and Vitality: Drains, liberalism and power in the nineteenth century. In: Barry, A., Osborne, T. \& Rose, N. (eds) Foucault and Political Reason - Liberalism, Neo-liberalism and Rationalities of Government. University of Chicago Press, pp. 99-121.

Pengilley, P. (1975). Aural Rehabilitation - Churchill Fellowship Report. Victorian Hear Service, Jolimont.

Plant, G.L. (1976). Aural Rehabilitation Programmes For Deafened Adults. Australian Journal of Human Communication Disorders, 4(1): 15-19. doi.org/10.3109/asl2.1976.4.issue-1.04

- - (1977). Adult Aural Rehabilitation - A Report On World Health Organisation Fellowship. National Acoustic Laboratory, Sydney.

Productivity Commission (2011). Disability Care and Support Report, No. 54, July 31. Canberra, Australia. 
Ross, M. (1997). A Retrospective Look at the Future of Aural Rehabilitation. Journal of the Academy of Rehabilitative Audiology, 30: 11-28.

Sherbourne, K. \& White, L. (1997). An Evaluation of the Impact of Rehabilitation Courses for Deafened Adults Run by the Link Centre for Deafened People. Manuscript.

Smeeth, L., Fletcher, A.E., Ng, E.S., Stirling, S., Nunes, M., Breeze, E., Bulpitt, C.J., Jones, D. \& Tulloch, A. (2002). Reduced Hearing, Ownership and Use of Hearing Aids in Elderly People in the UK the MRC Trail of the Assessment and Management of Older People in the Community: A cross sectional survey. Lancet, 359: 1466-70. doi.org/10.1016/S0140-6736(02)08433-7

Upfold, L.J. \& Isepy, J. (1982). Childhood Deafness in Australia. Incidence and Maternal Rubella, 1949-1980. The Medical Journal of Australia, 2(7): 323-26.

Westcott, S. \& Kato, J. (1998). 'Living with Deafness': A residential workshop to improve communication for deafened clients and partners. 13th Annual Conference, Australian Audiological Society, Novotel Hotel, Sydney.

Winefield, R. (1987). Never the Twain Shall Meet - The Communications Debate. Gallaudet University Press, Washington. 
This text is taken from Multi-level Governance: Conceptual challenges and case studies from Australia, edited by Katherine A. Daniell and Adrian Kay, published 2017 by ANU Press, The Australian National University, Canberra, Australia.

dx.doi.org/10.22459/MG.11.2017.08 